\title{
O GÊNERO CANISTRUM E. MORREN (BROMELIACEAE) NO ESTADO DO PARANÁ
}

\author{
Rosângela Capuano Tardivo ' \\ Armando Carlos Cervi
}

Recebido em 13/06/96. Aceito 31/12/97

\begin{abstract}
RESUMO - (O gênero Canistrum E. Morren (Bromeliaceae) no Estado do Paraná). Este trabalho é um estudo taxonômico das espécies do gênero Canistrum no Estado do Paraná. Canistrum cyathiforme (Vell.) Mez e C. lindenii (Regel) Mez são as únicas espécies pertencentes ao gênero, encontradas na flora paranaense. $C$. lindenii está restrita a três variedades e quatro formas: $C$. lindenii (Regel) Mez var. lindenii f. lindenii; $C$. lindenii var. viride (E. Morren) Reitz f. magnum Reitz; $C$. lindenii var. roseum (E. Morren) L. B. Sm. f. humile Reitz e C. lindenii var. roseum f. procerum Reitz. São apresentadas chaves de identificação, descrições, ilustrações e distribuição geográfica dos táxons estudados.
\end{abstract}

Palavras-chave : Canistrum, Bromeliaceae, taxonomia

\begin{abstract}
The genus Canistrum E. Morren (Bromeliaceae) in Paraná State). This work is a taxonomic study of Canistrum species in the Paraná State. Canistrum cyathiforme (Vell.) Mez and C. lindenii (Regel) Mez are the only species of the genus found in the flora of Paraná. C. lindenii is delimitted to three varieties and four forms: $C$. lindenii var. lindenii f. lindenii; $C$. lindenii var. viride (E. Morren) Reitz f. magnum Reitz; C. lindenii var. roseum (E. Morren) L. B. Sm. f. humile Reitz and C. lindenii var. roseum f. procerum Reitz. Identification keys, descriptions and geographical distribuition of the studied taxa are presented.
\end{abstract}

Key words: Canistrum, Bromeliaceae, taxonomy

\section{Introdução}

O Brasil é um dos três mais importantes centros de diversidade genética das espécies de Bromeliaceae. Os outros são os Andes, com prolongamentos em direção ao México e Antilhas, e o Planalto das Guianas (Smith \& Downs 1974). De acordo com Leme \& Marigo (1993), o leste brasileiro abriga a maior parte dos representantes da subfamília Bromelioideae, com 28 gêneros, destes, 11 são endêmicos, incluindo Canistrum.

\footnotetext{
Universidade Federal do Paraná, Centro Politécnico, Setor de Ciências Biológicas, Departamento de Botânica, Jardim das Américas, CEP 81531-970, Curitiba, PR, Brasil

Bolsa de Pesquisa, CNPq
} 
O gênero Canistrum foi criado por Édouard Morren em 1873, com base em $C$. aurantiacum. Baker (1889) enquadrou o gênero Canistrum como um subgênero de Aechmea Ruíz \& Pavon. Assim, todas as espécies até então descritas para o gênero em questão foram transferidas para Aechmea. Mez (1891) restaurou o gênero Canistrum e o enquadrou na Tribo Bromelieae, na subtribo Poratae Mez, seção Nidularinae Mez, juntamente com Nidularium Lem., e citou oito espécies para Canistrum, enquadrandoas em dois subgêneros: Subg. I- Nidulariopsis Mez, com uma única espécie, $C$. amazonicum Mez, atual Wittrockia amazonica (Baker) L. B. Sm. e subg.II- Eucanistrum Mez, no qual foram incluídas C. aurantiacum E. Morren, C. regnelli Mez, C. cyathiforme Mez, C. viride E. Morren, C. roseum E. Morren, C. lindenii (Regel) Mez e C. fuscum E. Morren.

Mez (1896) sinonimizou o subgênero Nidulariopsis e adotou Wittrockia Lindman como subgênero de Canistrum, no qual incluiu C. superbum Mez (atual W. superba Lindman), além de C. amazonicum Mez.

Mez (1934-35) enquadrou o gênero em questão na subfamília Bromelioideae Harms, tribo Poratae Mez, subtribo Nidulariinae Mez. Acrescentou ao subgênero Wittrockia (Lindman) Mez, C. minutum (Mez) L. B. Sm., atual W. minuta (Mez) L. B. $\mathrm{Sm}$. Além disto, o autor criou o subgênero Graviopsis $\mathrm{Mez}$, baseado em C. aurantiacum Mez. Esta espécie que até então enquadrava-se no subgênero Eucanistrum Mez, permaneceu como espécie única no novo subgênero.

Smith \& Downs (1979) apresentaram várias mudanças para o gênero em questão. Não consideraram os subgêneros Eucanistrum Mez e Graviopsis Mez e elevaram o subgênero Wittrockia ao nível de gênero. Nesta obra foram citadas sete espécies. Além destas, mais quatro espécies foram acrescentadas para a flora brasileira.

\section{Material e métodos}

O material para esta pesquisa foi obtido através de coletas realizadas no Estado do Paraná. Foram analisados ainda vários materiais-tipo, ou fotos destes, e coleções provenientes dos herbários relacionados: B, GH, HB, HBR, LG, M, MBM, PKDC, RB, SP, UPCB e US.

A nomenclatura utilizada na descrição morfológica das espécies foi baseada em Mez (1891), Font Quer (1953), Stearn (1983), Smith \& Downs (1979), Brown \& Gilmartin (1984, 1989) Leme \& Martinelli (1986) e Leme (1993).

Para a identificação dos táxons utilizou-se os seguintes trabalhos: Mez (18911894), Smith \& Downs (1979) e Reitz (1983).

\section{Resultados e discussão}

Canistrum E. Morren, Belg. Hortic.23: 257, 1873.

Aechmea Ruiz \& Pavon subgên. Canistrum (Morren) Baker, Handb. Bromel.: 68.1889. Tipo: A. aurantiaca $(=$ C. aurantiacum $)$.

Mosenia Lindman, Sv. Vet-akad. Handl. III. 24(8): 27, 1891. Tipo: M. sicarius Lindman . Canistrum E. Morren subgên. Eucanistrum Mez, Mart.Fl.Bras. 3(3): 249. 1891. Tipo: C. aurantiacum E. Morren. 
Canistrum E. Morren subgên. Eucanistrum Mez, Pflanzenreich IV, 32: 65,67. 1934. Tipo: Tillandsia cyathiformis Vell. (tipo indicado erroneamente por Smith \& Downs, Fl. Neotropica 14(3): 1715. 1979).

Canistrum E. Morren subgên. Graviopsis Mez, Pflanzenreich IV, 32: 65,67. 1934. Tipo: C. aurantiacum E. Morren; nome ilegítimo.

Tipo: C. aurantiacum E. Morren, Belg.Hortic. 23: 257. 1873.

Planta terrestre, rupícola ou epífita, estolonífera ou não. Folhas 10-20, liguladas, suberetas, formando roseta amplamente aberta ou infundibuliforme; bainha elíptica, ovada ou estreitamente ovada, densamente coberta por escamas castanho-escuras em ambas as faces; lâmina geralmente ligulada, subereta, ápice obtuso-apiculado, agudo ou acuminado, leve ou distintamente estreitada em direção à base, canaliculada ou não, glabra ou subglabra, margem espinulosa. Escapo verde, róseo ou avermelhado, glabro ou muitas vezes coberto com densa lanugem escura. Brácteas do escapo 1-7, lanceoladas, suboblongas, lineares, ovais ou elipticas, geralmente escamosas, ápice agudo, apiculado ou acuminado, margem conspicuamente serreada. Inflorescência composta, corimbosa, muitas vezes capituliforme, ca. 30-500 flores. Brácteas primárias lanceoladas a largamente lanceoladas, linear-lanceoladas ou ovadas, acuminadas, agudas ou apiculadas, eretas ou levemente recurvadas, verdes, amarelas, róseas ou avermelhadas. Fascículos com 4-14 flores, subflabeliformes ou flabeliformes, sésseis ou curto-pedunculados, lanuginosos ou não. Brácteas florais ovaladas, lanceoladas, lineares ou oblongas, margem inteira ou levemente denticuladas na base, carenadas ou não, muitas vezes lanuginosas, ápice agudo-apiculado, acuminado ou obtuso. Flores sésseis ou curto-pediceladas. Sépalas geralmente assimétricas, livres ou conadas na base, estreitamente triangulares, elípticas, obovadas, suboblongas, oblongas ou ovadolanceoladas, glabras ou lanuginosas na base, alvas, esverdeadas, amarelas ou róseas, ápice acuminado, agudo, apiculado ou mucronado. Pétalas sublineares, obtusas, elípticas, oblongas ou estreitamente obovadas, alvas à esverdeadas, amarelas ou alaranjado-amareladas, livres, sustentando dois apêncides na base da face interna, ápice obtuso e cuculado, apiculado ou agudo. Estames inclusos, em duas séries, sendo uma livre e a outra com filetes adnatos às pétalas. Anteras na maioria lineares ou estreitamente elípticas, base obtusa, ápice agudo ou mucronado, dorsifixas à metade de seu comprimento ou a um terço acima da base. Grão de pólen inaperturado, exina lisa ou reticulada. Estigma espiral-conduplicado. Ovário ínfero, elíptico, ovado, trígono, cilíndrico ou clavado, glabro ou lanuginoso. Tubo epígino geralmente presente ou, mais raramente, ausente. Placentação subapical, apical ou axial. Óvulos obtusos, obovados ou caudados. Fruto baga, com sépalas persistentes. Sementes subfusiformes.

Distribuição geográfica: Pernambuco, Bahia, Espírito Santo, Minas Gerais, Rio de Janeiro, São Paulo, Paraná e Santa Catarina.

$\mathrm{O}$ gênero Canistrum E. Morren caracteriza-se pelas pétalas livres e apêndices na face interna. Estas características distinguem-no de Nidularium, que se caracteriza fundamentalmente por não possuir apêndices petaláceos. Uma única exceção é $C$. perplexum L. B. Sm. cujas pétalas, embora livres, são desprovidas de apêndices. 
Em $C$. cyathiforme e $C$. lindenii foram observados dois apêndices fimbriados na base de cada pétala. Devido à presença de apêndices, Canistrum pode ser considerado próximo de Wittrockia Lindman; no entanto, neste último gênero, as pétalas são sempre conadas acima da base, ou na própria base, formando um tubo.

A função dos apêndices ainda é pouco conhecida, pois existem dados escassos sobre a biologia de polinização de bromélias. No entanto, muitos autores concordam na correlação entre os apêndices e néctar. De acordo com Harms (1930), os apêndices ajudam a evitar a perda de néctar. Segundo Varadarajan \& Brown (1988), os apêndices são vestígios e parecem não funcionais em alguns táxons de Pitcairnioideae e, em outras espécies de Pitcairnia funcionam como "escamas nectaríferas", que auxiliam na retenção de néctar. Outras funções para os apêndices são possíveis como guias, condução (retenção ou liberação) e proteção contra a dessecação do néctar (Brown \& Terry 1992).

Dentro da família Bromeliaceae, as espécies do gênero Canistrum talvez sejam as que possuem o maior número de flores na inflorescência. Em $C$. lindenii, por exemplo, a inflorescência pode conter de 90 a 500 flores. A antese completa desta espécie pode levar de 2 a 3 meses (Smith \& Downs 1974). Este fato pode ser explicado devido ao pequeno número de flores, não mais que 8 , que se abrem ao mesmo tempo durante a floração, sendo o período de antese, de cada flor, de no máximo de 3-4 dias.

Em vários espécimes de $C$. lindenii var. roseum, pode-se observar que não existe seqüência ou regularidade na abertura das flores, como nas espécies de Nidularium. Assim, ao mesmo tempo, as flores do centro, bem como as flores da parte mais periférica da inflorescência podem desabrochar.

A Floresta Atlântica abriga todas as espécies conhecidas do gênero Canistrum; no entanto, algumas espécies, como $C$. cyathiforme, habitam também a Floresta Ombrófila Mista e os Campos Gerais. Algumas espécies são restritas a certas regiões. É o caso de $C$. aurantiacum, endêmica no Estado de Pernambuco e $C$. triangulare L. B. Sm. \& Reitz, exclusiva do Estado do Espírito Santo. Na Bahia, são encontradas $C$. fosterianum L. B. Sm. e a recém-descrita C. camacaensis Martinelli \& Leme. Aliás, este Estado é considerado uma das áreas mais ricas em bromélias endêmicas (Leme \& Marigo 1993).

A maioria das espécies do gênero Canistrum está concentrada entre os Estados de Minas Gerais e São Paulo. Nesta faixa, são encontradas seis das onze espécies conhecidas, entre elas, $C$. cyathiforme (Vell.) Mez e $C$. lindenii (Regel) Mez, as únicas que se estendem até a região Sul.

Chave para as espécies do gênero Canistrum no Estado do Paraná

1. Escapo floral e inflorescência glabros; bráctea do escapo 1 ou raramente 2; brácteas florais estreitamente lineares, acuminadas 1. C. cyathiforme

1. Escapo floral e inflorescência densamente lanuginosos; brácteas do escapo 4-7; brácteas florais oblongas, agudas ou obtusas 2. C. lindenii

1. Canistrum cyathiforme (Vell.) Mez in Mart., Fl. Bras. 3(3): 252. 1891

Fig.1-7 

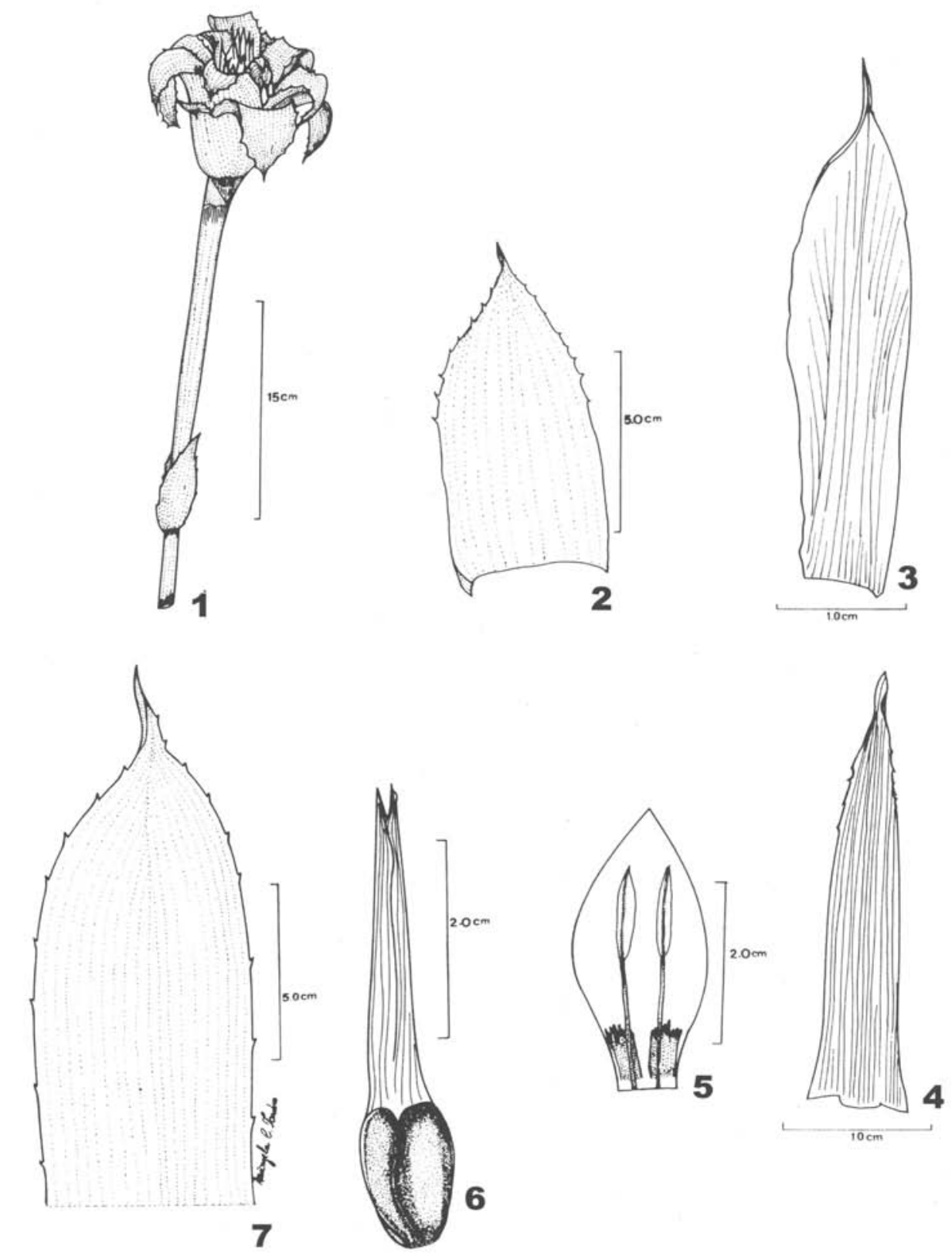

Figura 1-7 Canistrum cyathiforme (Vell.) Mez. 1.Inflorescência; 2.Bráctea primária; 3.Sépala; 4.Bráctea floral-face ventral; 5.Pétala; 6.Fruto, mostrando as sépalas persistentes; 7.Segmento apical da folha; (1-5; 7 : R.C.Tardivo et al. 154; 6: A.C.Cervi 3828). 
Tillandsia cyathiformis Vell., Fl. Flum. 137. 1825; Icon 3: pl.144. 1831.

Hohenbergia cyathiformis (Vell.) Beer, Bromel. 73. 1856; como "cyanthiformis". Karatas regnellii Baker, Handb. Bromel. 10. 1889; pro-parte.

Guzmania sallieri Hortus ex Baker, Handb. Bromel. 152. 1889. nomen nudum

Mosenia sicarius Lindman, Sv.Vet-Akad. Handl. Ill. 24(8):21.1891. Tipo: Pedra Branca, Caldas,

Minas Gerais , Brasil, Regnell III-1259 (B, foto f 11303; S, US).

Canistrum regnellii Mez in Mart., Fl. Bras. 3(3): 252. 1891, pro-parte.

Canistrum schwackeanum Mez, Bot. Jahrbr. 30 (Bleibl.67): 4. 1901.Tipo: Ouro Preto, Minas

Gerais, Brasil, 20/VII/1894. Schwacke 10558 (B, foto B 1195/1; RB).

Planta $52-73 \mathrm{~cm}$ de alt., epífita, rupícola ou terrestre. Folhas 12-19, suberetas, rosuladas; bainha $13-18 \mathrm{~cm}$ compr., $7-13 \mathrm{~cm}$ larg., elíptica ou oval, margem inteira ou serreada em direção ao ápice, densamente coberta por escamas castanho-escuras em ambas as faces; lâmina ligulada $55-75 \mathrm{~cm}$ compr., $5-7 \mathrm{~cm}$ larg., levemente estreitada em direção à base, verde, marmorizada com manchas verde-escuras, em ambas as faces com escamas castanhas, especialmente na face abaxial, margem espino-serreada, espinhos 0,1-0,4cm compr., distanciados entre si por $0,8-1,2 \mathrm{~cm}$, castanhos, ápice subarredondado e apiculado. Escapo ereto, glabro, $27-50 \mathrm{~cm}$ compr., $0,8 \mathrm{~cm}$ diâm., róseo escuro ou vermelho escuro. Bráctea do escapo 1, raramente 2, lanceolada, geralmente fixada na parte mediana ou mais próxima da inflorescência, $6,8-7,5 \mathrm{~cm}$ compr., margem serreada, ápice agudo-acuminado, rósea no ápice e verde em direção à base. Inflorescência composta, subcorimbosa, $7-9 \mathrm{~cm}$ compr., $3-4 \mathrm{~cm}$ diâm. na parte superior, incluindo as brácteas. Brácteas primárias $8,5-9,0 \mathrm{~cm}$ compr., 3-4cm larg., lanceoladas, róseas ou avermelhadas, densamente escamosas em ambas as faces, margem serreada em direção ao ápice, dentes ca. $0,2 \mathrm{~cm}$ compr., distanciados entre $0,2-0,6 \mathrm{~cm}$, róseos, ápice obtuso ou acuminado. Ramos com 3-6 flores, compostos, subflabeliformes. Brácteas florais 4,0$4,5 \mathrm{~cm}$ compr., ca. $0,7 \mathrm{~cm}$ larg., lineares, acuminadas, alvas, glabras, margem insconspicuamente serreada em direção ao ápice. Flores 4,5-5,5cm compr., subsésseis, concêntricas na inflorescência; sépalas $2,5-3,5 \mathrm{~cm}$ compr., livres, estreitamente lanceoladas, levemente assimétricas, acuminadas, glabras, branco-esverdeadas; pétalas ca. $3,5 \mathrm{~cm}$ compr., livres, largamente lanceoladas, amarelas, alaranjado-amareladas em direção ao ápice, sustentanto dois apêndices fimbriados na base da face interna, ápice agudo à arredondado; estames inclusos; anteras ca.0,5cm compr., base obtusa, ápice agudo; ovário subcilíndrico ou levemente elipsóide, tubo epigínico nulo; placentação axial; rudimentos seminais elípticos. Fruto baga, com sépalas persistentes, ca. $1,5 \mathrm{~cm}$ compr., amarelo-alaranjado.

Tipo: Não se conhece a localidade correta, mas presume-se ser do Rio de Janeiro, próximo à divisa com o Estado de São Paulo. Tipificada a partir da estampa de Vellozo, Flora Fluminensis, Icon 3: pl. 144.1831.

Distribuição geográfica: Santa Catarina, Paraná, São Paulo, Minas Gerais, Rio de Janeiro e Espírito Santo.

Material examinado: BRASIL. Paraná: Arapotí, 15/VI/1960, Seidel s.n.(HBR); Rio das Perdizes, 06/ IV/ 1970, Hatschbach 24110 (MBM); Campina Grande do Sul, Sítio do Belizário, 16/XI/1967, Hatschbach 17880 (MBM); Encosta Leste do Morro 
Anhangava, XII/1959 Hatschbach et Smith 960 (MBM); Jaguariaiva, 23/IV/1911, Dusén 11716 (US); Morretes: Serra da Graciosa, 17/III/1994, Tardivo et al. 154, (UPCB); Piraquara, Alto da Serra, 14/XII/1952, Hatschbach et Smith 953 (MBM); Quatro Barras: Morro 7, Cervi et al. 3828, 07/XI/1992 (UPCB); Morro 7, 06/III/ 1993, Tardivo et al. 124 (UPCB); São José dos Pinhais, Barro Branco, 11/XI/1965, Hatschbach et Smith 967 (MBM); São Mateus do Sul, 20/VII/1986, Souza et al. s.n., (PKDC); Serra do Mar, banhado, 30/XII/1915, Dusén 15489b (US); Tibagi: Quartelá, Canyon Rio Iapó, 10/X/1992, Hatschbach et Barbosa 58215, (MBM); Santa Catarina: São Francisco do Sul, Morro do Campo Alegre, 23/III/1961, Reitz et Klein 10972 (US). São Paulo: São Paulo, Serra da Bocaina, Morro do Matão, 16/V/1951, Brade 21150 (US); Campos da Bocaina, Mata ciliar próximo à cachoeira de Santo Isidro, 02/V/1959, Pabst 4824 (HB). Minas Gerais: Caldas, Pedra Branca, 01/V/1873, Regnell 1259 (US). Rio de Janeiro: Teresópolis, 22/VII/1940, Mulford et Foster 1014 (US). Espírito Santo: sem local definido, 03/VIII/1973, Seidel 661 (HB).

Esta espécie tem distribuição bastante ampla em todo o Brasil, ocorrendo na região sul e em toda a região sudeste. No Paraná, Canistrum cyathiforme não é exclusiva da floresta atlântica, como a maioria das espécies do gênero. É encontrada também em outros tipos vegetacionais, como a Floresta Ombrófila Mista e alguns locais recobertos pelos Campos Gerais.

C. cyathiforme é planta esciófila, de hábito terrestre, rupícola ou epífita. Caracteriza-se pelas sépalas estreitamente triangulares, levemente assimétricas e acuminadas. As lâminas foliares são pontuadas, com manchas verde-escuras em toda a sua extensão. A inflorescência, com escapo róseo a vermelho-escuro, bastante alongado, e brácteas que configuram uma taça, diferenciam esta espécie das demais. Floresce de novembro a março.

2. Canistrum lindenii (Regel) Mez in Mart., Fl.Bras.3(3): 256. 1891.

Fig. 8-17

Planta $48-60 \mathrm{~cm}$ alt., terrestre, rupícola ou epífita. Folhas 15-20, rosuladas, suberetas; bainha 14-18cm compr., 11-13,5cm larg., elíptica, em ambas as faces verdeclaras, tornando-se róseas ou alvas em direção à base, densamente coberta por escamas castanho-escuras, margem inteira; lâmina ligulada, ca. $74 \mathrm{~cm}$ compr., ca. $40 \mathrm{~cm}$ larg., canaliculada em direção à base, verde e, em ambas as faces marmorizadas com manchas verde-escuras, esparsamente lepidotas, margem espinulosa, espinhos ca. $0,1 \mathrm{~cm}$ compr., distanciados entre si por 0,5-4mm, verdes ou avermelhados, ápice obtuso ou acuminado. Escapo ereto, $9-20 \mathrm{~cm}$ compr., ca. $0,8 \mathrm{~cm}$ diâm. , imerso no centro da roseta ou elevado, coberto com lanugem densa, ferrugíneo-escura. Brácteas do escapo 4-7, parcialmente imbricadas, ovadas, margem levemente serreada, dentes ca. $0,8 \mathrm{~mm}$ compr., escamosas em ambas as faces. Inflorescência composta, densamente corimbosa, capituliforme, 8,3-9,2cm compr., 6-7cm diâm. na parte superior, incluindo as brácteas. Brácteas primárias ca. $10 \mathrm{~cm}$ compr., ca. $4,5 \mathrm{~cm}$ larg., largamente lanceoladas, acuminadas, róseas ou avermelhadas, margem serreada em direção ao ápice, dentes $0,8-1 \mathrm{~mm}$ compr., róseos, distanciados entre sí entre 0,8-1,2cm. Ramos compostos de 6-14 flores, ca. $5 \mathrm{~cm}$ 


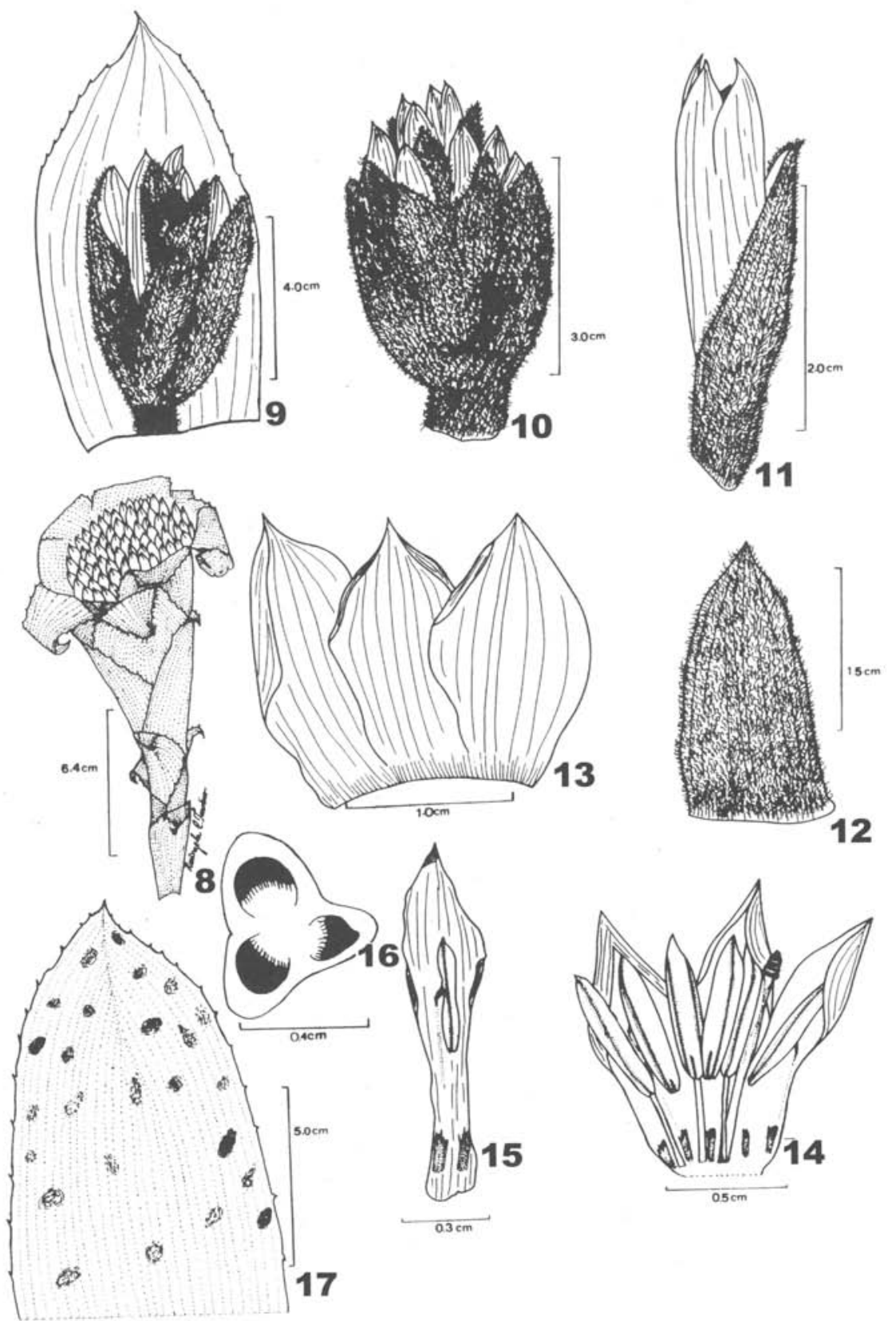

Figura 8-17-Canistrum lindenii (Regel) Mez var. roseum (Morren) L. B. Sm. f. humile Reitz. 8.Inflorescência; 9.Bráctea primária e Ramo; 10.Ramo; 11.Flor e Bráctea floral; 12.Bráctea floral-face dorsal; 13.Sépalas; 14.Pétalas; 15.Pétala, mostrando o par de apêndices basais; 16.Corte transversal do ovário; 17.Segmento apical da folha. (R.C.Tardivo 150), 
compr., $3 \mathrm{~cm}$ larg., lanuginosos, pedicelo ca. $1 \mathrm{~cm}$ compr. e 1,3cm larg. Brácteas florais oblongas, agudas ou obtusas, um pouco menores que as flores, alvas, cobertas com densa lanugem castanho-escura. Flores 90-500, ca. 3,5cm compr., curto-pediceladas, pedicelo ca. $0,5 \mathrm{~cm}$ compr.; sépalas ca. $1,6 \mathrm{~cm}$ compr., $0,9 \mathrm{~cm}$ larg., conadas por ca. $0,3 \mathrm{~cm}$, assimétricas, elípticas, acuminadas, alvas, lanuginosas em direção à base; pétalas 1,0-1,4cm compr., $0,4-0,5 \mathrm{~cm}$ larg., oblongas ou estreitamente obovadas, alvas na base e esverdeadas em direção ao ápice, lâminas sobrepostas, involutas, livres somente na antese, excedendo ligeiramente as sépalas, sustentando dois apêndices fimbriados na base, ápice apiculado; estames inclusos, em duas séries, uma epipétala, com filetes concrecidos por cerca da metade de seu comprimento, a outra alterno às pétalas, com os filetes livres; anteras ca. $0,6 \mathrm{~cm}$ compr., lineares, amareladas, base obtusa, ápice agudo; ovário subclavado, ca. $0,6 \mathrm{~cm}$ compr., $0,4 \mathrm{~cm}$ diâm., alvo, densamente lanuginoso; tubo epígino $0,3 \mathrm{~cm}$ compr.; placentação axial; óvulos obovados. Fruto baga, ca. $1,0 \mathrm{~cm}$ compr., alvescentes.

Inicialmente esta espécie foi descrita como Nidularium lindenii por Regel (1869). No entanto, a morfologia muito variável apresentada pela planta quanto à coloração das brácteas primárias, o comprimento do escapo floral e o número de flores na inflorescência, ocasionou a criação de várias espécies novas.

Morren (1873) apud Reitz (1950) descreveu Canistrum viride e, em 1879, C. roseum. Apesar de mofologicamente muito semelhantes, o autor considerou a coloração das brácteas involucrais um bom caráter diagnóstico para separá-las.

Mez (1891) propôs nova combinação, C. lindenii, baseando-se em Nidularium lindenii Regel. O autor diferenciou C. lindenii, $C$. viride e $C$. roseum não somente pela coloração das brácteas primárias, mas também conferiu algumas variações no formato das brácteas florais e no tamanho das flores. Após vários anos de estudos, Reitz (1950) verificou que a forma das brácteas florais das três espécies variava desde o ápice agudo até obtuso e, quanto às flores, o autor não constatou divergência alguma. A partir destas observações, Reitz (1950) e Smith (1950) concluiram que tais diferenças entre as espécies poderiam justificar apenas a manutenção de variedades. Foi então que os autores reduziram $C$. viride e $C$. roseum às variedades de $C$. lindenii.

A extrema variação na altura do escapo floral observada entre indivíduos da mesma variedade, induziu Reitz (1950) a criar duas formas para cada uma das variedades: forma exiguum Reitz que referia-se à planta cujo escapo era muito curto, inteiramente imerso na roseta foliar, e a forma elatum Reitz, caracterizada pelo escapo floral muito elevado, $20 \mathrm{~cm}$ ou mais acima da roseta das folhas.

Reitz (1952) alterou os nomes das formas de C. lindenii pois, tanto a forma elatum quanto a forma exiguum foram, publicadas simultaneamente para as três variedades da espécie. Esta correção resultou em: $C$. lindenii var. lindenii $\mathrm{f}$. lindenii (antiga f. exiguum); C. lindenii var. viride f. parvum (antiga f. exiguum); C. lindenii var. viride f. magnum (antiga forma elatum); C. lindenii var. roseum f. humile (antiga forma exiguum) e C. lindenii var. roseum f. procerum (antiga forma elatum).

Canistrum lindenii caracteriza-se por apresentar inflorescência densamente corimbosa, com 90-500 flores e pela lanugem marrom-escura recobrindo o escapo e partes florais. As folhas, apesar de pouco numerosas, formam grande roseta amplamente 
aberta, com grande capacidade de retenção de água. As escamas foliares apresentam escudo circular com um grupo central de células. Em estado vegetativo é praticamente impossivel diferenciá-la de $C$. cyathiforme (Vell.) Mez, assim como já observara Smith (1967), pois ambas as espécies apresentam lâminas foliares densamente marmorizadas com manchas verde-escuras. É uma espécie esciófila ou heliófila, ocorrendo como terrestre, vivendo na serapilheira do chão da Floresta Atlântica, rupícola ou epífita, em níveis bem próximos do solo ou em galhos mais altos, até 6 metros.

Ao que tudo indica, Canistrum lindenii parece estar mais concentrada no sul do Brasil, embora também ocorra no Estado do Rio de Janeiro.

Chave para a identificação dos táxons infraespecíficos de Canistrum lindenii no Estado do Paraná

1. Brácteas primárias amareladas a quase alvas, às vezes levemente verdes em direção ao ápice, ou inteiramente verdes

2. Inflorescência com 100- 500 flores, escapo floral ca. $10 \mathrm{~cm}$ compr.

2.1. var. lindenii f. lindenii

2. Inflorescência com 50-90 flores, escapo floral ca. $20 \mathrm{~cm}$ compr

2.4. var. viride f. magnum

1. Brácteas primárias róseas a avermelhadas

3. Escapo floral ca. $20 \mathrm{~cm}$ comprimento, elevando a inflorescência acima da roseta foliar 2.2. var. roseum f. procerum

3. Escapo floral $9-10 \mathrm{~cm}$ de comprimento; inflorescência imersa no centro da roseta foliar 2.3. var. roseum f. humile

Canistrum lindenii (Regel) Mez var. lindenii Anais Bot. Herb. Barbosa Rodrigues 2: 36, 1950.

Nidularium lindenii Regel, Ind.Sem. Hort. Petrop. 1868: 78.1869.

Guzmania fragans Linden Hortus ex Regel, Ind. Sem. Hort. Petrop. 1868: 78.1869 nomen nudum

Canistrum eburneum E.Morren, Belg. Hort. 28: 207. 1878 .

Aechmea eburnea (E.Morren) Baker, Handb. Bromel.: 69. 1889.

Esta planta caracteriza-se pelas brácteas primárias amareladas a quase alvas, às vezes, levemente verdes em direção ao ápice e pelo grande número de flores na inflorescência, 100-500. Possui distribuição bastante restrita, ocorrendo exclusivamente no sul do Brasil. Reitz (1983) citou ambas as formas (lindenii e elatum) para Santa Catarina. No Paraná apenas uma forma foi encontrada.

\subsection{Canistrum lindenii (Regel) Mez var. lindenii f. lindenii}

Canistrum lindenii var. lindenii f. exiguum Reitz, Anais Bot. Herb. Barbosa Rodrigues 2: 37. 1950.

Esta planta possui o escapo floral muito curto, ca. $10 \mathrm{~cm}$ compr. Por esta razão, a inflorescência permanece imersa no centro da roseta foliar ou levemente elevada.

Este táxon apresenta dispersão restrita, encontrado, até o momento, exclusivamente na Floresta Atlântica. No Paraná pode ser considerada rara, pois um único exemplar foi coletado na região de Guaraqueçaba, litoral do Estado. 
Tipo: Brasil, Petrograd Hortus s.n. (Lectótipo: LE, n.v.) Tipificado pela descrição original e pela ilustração do espécime introduzido na horticultura por Lindley e elaborada por E.Morren, Belg. Hortic. 29: 168. est. 13. 1879.

Distribuição geográfica: Paraná e Santa Catarina.

Material examinado: BRASIL. Paraná: Guaraqueçaba, arredores, 20/III/1992, Hatschbach 56438 (MBM). Santa Catarina: Brusque, VI 1950, Reitz 3646 (HBR); Florianópolis, Morro Itacorubí, 12/III/1952, Smith et Reitz 6153 (US).

Canistrum lindenii (Regel) Mez var. roseum (E.Morren) L. B. Sm., Anais Bot. Herb. Barbosa Rodrigues 2: 14. 1950.

Canistrum roseum E. Morren, Belg. Hortic. 29: 301. 1879.

Aechmea rosea (E. Morren) Baker, Handb. Bromel.: 68.1889.

Canistrum bellarosa Fritz Muller ex Ule, Bericht. Deutsch. Bot. Gesellsch. 17: 54. 1889; nomen nudum

Tipo: Brasil, cultivado em Comte de Germany, Morren s.n. ( Holótipo LG).

Esta planta destaca-se na floresta devido à coloração viva, rósea à avermelhada, de suas brácteas primárias e florais. O número de flores na inflorescência varia entre 92-120. Dentre as variedades da espécie, $C$. lindenii var. roseum é a mais freqüente em todo o Brasil. No Paraná, habita desde o nível do mar até 800 metros de altitude.

2.2. Canistrum lindenii (Regel) Mez var. roseum (E. Morren) Smith f. procerum Reitz, Anais Bot. Herb. Barbosa Rodrigues 4:19.1952.

Canistrum lindenii (Regel) Mez var. roseum (E. Morren) L. B. Sm. f. elatum Reitz, Anais Herb. Barbosa Rodrigues 2:38.1950 nomen nudum

Tipo: Brasil, Santa Catarina: Botuverá, Ribeirão do Ouro, 16/V/1950, Reitz s.n. (holótipo HBR, n.v.).

Caracteriza-se por apresentar escapo floral longo, 19-20cm compr., elevando a inflorescência até $20 \mathrm{~cm}$ acima da roseta foliar. Vive como epífita nos galhos mais altos das árvores; raramente observam-se indivíduos rupícolas ou terrestres. Floresce nos meses de fevereiro a agosto.

Material examinado: BRASIL. Paraná: Morretes, Estrada da Graciosa, 06/III/1993, Tardivo et al. 120 (UPCB); Rio Nhundiaquara, Parque Estadual do Pico do Marumbi, 23/II/994, Tardivo et al. 144 (UPCB); Santa Catarina: Brusque, 08/V/1950, Reitz 3561 (US). Rio de Janeiro: Fazenda Rocio, BR 135, 28/VIII/1967, Pereira 10621 (MBM, HB).

2.3. Canistrum lindenii (Regel) Mez var. roseum (E. Morren) L. B. Sm. f. humile Reitz, Anais Bot. Herb.Barbosa Rodrigues 4: 19. 1952.

Canistrum lindenii (Regel) Mez var. roseum (E. Morren) L. B. Sm. f. exiguum Reitz, Anais Bot. Herb. Barbosa Rodrigues, 2: 37. 1950. nomen nudum

Tipo: Brasil, Santa Catarina: Brusque, IX/1950, R. Reitz 3671 (Holótipo HBR, n.v.). 
Diferencia-se da forma procerum Reitz por apresentar a inflorescência imersa no centro da roseta foliar, devido ao escapo floral muito curto, com $9-10 \mathrm{~cm}$ compr.

Preferencialmente, ocorre como epífita nos estratos mais baixos das árvores, próximas ao solo, ou nos estratos mais altos, até 12 metros. Vive em agrupamentos de 3-4 indivíduos; raramente observam-se indivíduos isolados. Floresce nos meses de janeiro a junho.

Material examinado: BRASIL. Paraná: Estrada Velha Curitiba-Joinville, Km 72, Rio São João, 12/III/1994, Tardivo et al. 150 (UPCB); Guaraqueçaba, Rio do Cedro, 21/V/1968, Hatschbach 19236 (MBM). Morretes, Serra da Graciosa, 04/III/1993, Tardivo et al. 117 (UPCB); Pontal do Sul, Praia de Leste, 21/IV/1972, Leinig 498 (HB).Santa Catarina: Brusque, 03/XI/1949, Reitz 3181 (HBR, US); Ilhota, Morro do Baú, 30/I/1964, Pereira 8753 et Pabst 8028 (MBM,HB).

Canistrum lindenii (Regel) Mez var. viride (E. Morren) Reitz, Anais Bot. Herb. Barbosa Rodrigues 2: 38. 1950.

Canistrum viride E. Morren, Catal. 7. 1873.

Aechmea viridis (E. Morren) Baker, Jour. Bot. London 17: 235. 1879.

Bilbergia canephora Hortus ex Baker, Handl. Bromel. 69. 1889 nomen nudum

Esta planta caracteriza-se por suas brácteas primárias e florais totalmente verdes. Apresenta de 50- 90 flores na inflorescência.

2.4. Canistrum lindenii (Regel) Mez var. viride (E. Morren) Reitz f. magnum Reitz Canistrum lindenii (Regel) Mez var. viride (E. Morren) Reitz f. elatum Reitz, Anais Herb.

Barb. Rodrigues 2: 38.1950 nomen nudum

Tipo: Brasil, Paraná: Ilha das Peças, APA de Guaraqueçaba, Baia de Paranaguá. Holótipo não designado.

Caracteriza-se por apresentar o escapo floral longo, ca. $20 \mathrm{~cm}$ comprimento, elevando a inflorescência muito acima da roseta foliar.

Estudos realizados por Reitz (1950; 1983) e Smith \& Downs (1979) indicam que o material tipo desta variedade foi coletado na Ilha das Peças, Área de Proteção Ambiental de Guaraqueçaba, Estado do Paraná e encontra-se depositado no herbário de Liège, Bélgica. No entanto, de acordo com o professor J. Lambinon, diretor daquele herbário, o holótipo de $C$. lindenii var. viride não se encontra determinado, mas algumas exsicatas do material original poderiam servir para a designação de um lectótipo, quando da revisão taxonômica do gênero. Apesar da intensa busca, não foi localizado nenhum outro exemplar no Estado do Paraná.

Material examinado: BRASIL. Santa Catarina: Brusque, 16/V/1950, Reitz s.n. (HBR).

\section{Agradecimentos}

Os autores agradecem ao professor Dr. William A Rodrigues e ao professor Olavo A. Guimarães por suas valiosas sugestões. 


\section{Referências bibliográficas}

Baker, J. G. 1889. Handbook of the Bromeliaceae. London. George Bell \& Sons.

Brown, G. K. \& Gilmartin, A. J. 1984. Stigma Structure and variation in Bromeliaceae- negleted taxonomic characteres. Brittonia 36(4): 364-374.

Brown, G. K. \& Gilmartin, A. J. 1989. Stigma types in Bromeliaceae - A systematic survey. Systematic Botany 14(1): 110-132.

Brown, G. K. \& Terry, R. G. 1992. Petal appendages in Bromeliaceae. American Journal Botany 79 (9): 1051-1071.

Font Quer, P. 1953. Dicionário de Botánica. Barcelona. Labor.

Harms, H. 1930. Bromeliaceae p.65-69. In: A. Engler, Prantl, Nat.Pflanzenfam. 2 ed., v. 15 a

Leme, E. M. C. \& Martinelli, G. 1986. Novas Bromeliáceas nativas do Brasil-iii. Bradea 4(33): 254-259.

Leme, E. M. C. 1993. Novas Bromeliáceas nativas do Brasil-X. Pabstia 4(3): 1-16.

Leme, E. M. C. \& Marigo, L. C. 1993. Bromélias na natureza. Rio de Janeiro. Marigo Comunicação Visual Ltda.

Mez, C. Bromeliaceae. 1891-1894. In: Martius,C.F.P. Flora Brasiliensis. Weinheim. J.Cramer, 3(3):173634.

Mez, C. Bromeliaceae. 1896. In: C. De Candolle, Monographiae Phanerogamarum. Paris. Sumptibus Masson. $9(61): 1-144$.

Mez., C. Bromeliaceae. 1934-1935. In: A. Engler, Das Pflanzenreich. Stuttgart. 14 (32): 38-70.

Reitz, R. 1950. Notas sobre o gênero Canistrum em Santa Catarina. Anais Botânicos Herbário Barbosa Rodrigues 2: 35-38.

Reitz, R. 1952. Species, Varietates, Combinationes novae et Critcae Bromeliacearum catharinensium. Anais Botânicos Herbário Barbosa Rodrigues, 4: 7-36.

Reitz, R. 1983. Bromeliáceas e a Malária - Bromélia endêmica. Flora Ilustrada Catarinense: 1-608.

Reitz, R. 1984. Canistrum lindenii var.pehnkii n.var. Sellowia: 36:63.

Smith, L.B. 1950. Notas sobre Bromeliáceas de Santa Catarina. Anais Botânicos Herbário Barbosa Rodrigues 2: $13-15$.

Smith, L.B. 1967. A identificação de Bromeliáceas estéreis. Sellowia 19: 119-123.

Smith, L.B. \& Downs, R. J. 1974. Pitcairnioideae (Bromeliaceae). Flora Neotropica Monograph 14 (1): 1 658.

Smith, L.B. \& Downs, R. J. 1979. Bromelioideae (Bromeliaceae). Flora Neotropica Monograph 14 (3): 1604-1724.

Stearn, W.T. 1983. Botanical Latin. 3 ed. Devon. David \& Charles. 566p.

Varadarajan, G. S. \& Brown, G. K. 1988. Morphological variation of some floral features of the subfamily Pitcairnioideae (Bromeliaceae) and their significance in pollination biology. Botanical Gazette 149 (1): $82-91$. 